\title{
5. The mixed self-interest in the welfare state
}

In this chapter, we describe the wage income, benefit incomes, and tax payments of the 14 migrant groups of the book. This information is available to us via the register data linked to the original survey data. Typically, surveys only include rough measures of self-assessed income. The register data allow for a more precise and fine-grained description of taxes and various kinds of income. This is useful not only for the descriptive intents of this chapter but also for later analyses of the effects of socio-economic factors (box 3 in Figure 1.1, in Chapter 1) on welfare attitudes (box 1). The register data will further highlight how our surveys cover an array of apparently quite different migrant groups. A few of these groups are very similar to native Danes as regards the wages and benefits they receive as well as the taxes they pay. A few of the groups earn little in wage incomes, pay little in taxes, and are generally very dependent on welfare benefits. Most of the groups have relatively low wage incomes, but also receive a little less in income benefits than native Danes. Thus, the various groups have different levels of vested interests in the Danish welfare state.

In the literature, various indicators of individual socio-economic position (SEP) are typically included as variables to investigate the role of self-interest from a rational choice perspective. It is sometimes simply assumed that individuals with low SEP stand to gain more from a welfare state and therefore they are generally in favour of welfare benefits and services. However, benefit recipiency, which we can capture in nuance with the Danish register data, is a more precise and valid indicator when seeking to sort out self-interest. Since some migrant backgrounds face many barriers for labour market entry, and so may on average be more dependent on the welfare state, migrant status by itself has sometimes been used as an indicator of self-interest for a high-risk group (Blomberg, Kallio, Kangas, Kroll, \& Niemelä, 2012). This is also too simple. Others have considered individual differences in SEP for migrants. Reeskens \& van Oorschot (2015), for instance, find that differences in SEP relate modestly to welfare attitudes among migrants across European countries. This chapter proceeds to operationalize indicators that are better suited to assess the potential effect of self-interest. Utilizing the register data, we can, at the individual level, precisely measure different kinds of benefits and 
the amounts received, as well as taxes paid. For instance, this chapter will show how particularly migrants from Great Britain and the US gain very little from the Danish welfare state, while they pay more in taxes due to high wage incomes. Most of the other groups in the Mifare survey earn smaller wages relative to native Danes, but they are not necessarily more dependent on the welfare state. Often, they receive a little less in income benefits as well. The migrant groups from the Comcon survey, however, are generally more reliant on public income benefits, while fewer earn wage incomes. This applies particularly to the migrants from ex-Yugoslavia, Iraq, and Lebanon.

The chapter starts by outlining the entitlement criteria for various income benefits in Denmark while paying special attention to residency requirements that in particular affect migrants' access to the benefits. The remaining bulk of the chapter describes differences across our 14 migrant groups concerning wage income, benefit income, and tax payments. It should be noted that we do not include data on the consumption of public services such as education, healthcare, or care services for children and the elderly. Such measures are not readily available with register data, or rather, they further require complicated assumptions and estimates concerning the value of these services (Verbist, 2017). Generally, various studies in the field find that public services further reduce inequality (Verbist, 2017). This applies to Denmark as well (Ploug, 2017). However, there is no doubt that our migrant groups and respondents also vary significantly concerning their consumption of public services, and these variations may not simply follow the pattern that we see with regards to income benefits. Finally, it should be noted that both benefits and services might have an insurance effect, that is, they might have value even for those who do not consume these benefits and services at the moment. Thus, it is by no means an easy task to calculate how the institutional structure of destination countries (box 4 in Figure 1.1) shapes migrants' self-interest in the welfare state. However, the chapter establishes some first rough estimates for the Danish context.

\section{INCOME BENEFITS AND SOCIAL RIGHTS IN WORKING AGE}

The income benefits we will cover here are unemployment insurance, social assistance, and disability pension. These are the main benefit schemes for working-age people who are either considered unemployed (unemployment insurance and recipients of social assistance deemed "ready for work") or outside of the labour force (disability pension and recipients of social assistance deemed "ready for activity", that is, training, activation, and subsidized employment). We also provide information on the major supplementary benefits that are not particular to labour market status and may be combined with 
the other schemes, namely child support and housing benefits. Later analyses in this chapter will divide benefit incomes into these schemes.

Generally, there is some degree of myth-making regarding the generosity of income benefits in Denmark and the Nordic countries. When measured via compensation rates, that is, benefits levels in relation to previous wages, most income benefits for working-age people in Denmark and the other Nordic countries (except Norway) have regressed towards the OECD average over the last few decades (Dølvik, Andersen, \& Vartiainen, 2015; Kongshøj, 2014; Pedersen \& Kuhnle, 2017). The particularities of the "Nordic model" are more evident in other areas of social policy. What has been a Nordic particularity is the coverage or inclusivity rather than the generosity; meaning that very few have been excluded altogether from either the labour market or access to social benefits and services. This characteristic still applies to some extent. However, a series of reforms within the last decade also have resulted in a more insecure situation for some groups, particularly long-term unemployed or people who previously would be eligible for disability pensions (Dølvik, Andersen, \& Vartiainen, 2015; Kongshøj, 2014). There have also been several reforms in Denmark, which directly reduce migrants' entitlements to social assistance. Table 5.1 describes the eligibility rules, with special attention to rules directed at immigrants, and general benefit amounts as they were in 2018. It should be noted that the rules apply to 2018 and that some of them were slightly different in 2015/2014 when the two surveys were fielded. These differences are summarized in Table 5.1 .

Over time, the general trend has been towards lower benefit levels and stricter eligibility rules. Rules that additionally affect immigrants are noteworthy. In social assistance there has been some degree of political contestation and policy fluctuation; lower benefit levels targeting immigrants were first adopted in 1998 and removed again in 2000 by the same centre-left government. A new right-wing government re-introduced this measure in 2002, but it was abolished in 2011 when a centre-left coalition came to power once again. After government power switched back towards the right in 2015, the present "integration assistance" was adopted (Breidahl, 2012; Schultz-Nielsen \& Hansen, 2017). The benefit was reduced further in 2019 and re-named "repatriation benefit" for people with a refugee background. As regards other income benefits, new or stricter residency requirements have been a more recent, but steady trend. Residency requirements for full child support were introduced in 2010 and were raised to the present six years (within the most recent ten years) from 2018 (Table 5.1). In 2017, it was decided that the present 4/5-requirement for full disability benefits (as explained in the table) would be raised to a 9/10 requirement from 2019. Migrants with a refugee background were previously exempted from the residency requirements for full disability (and old age) pension indicated in Table 5.1, but this exemption was removed in 2015 for 


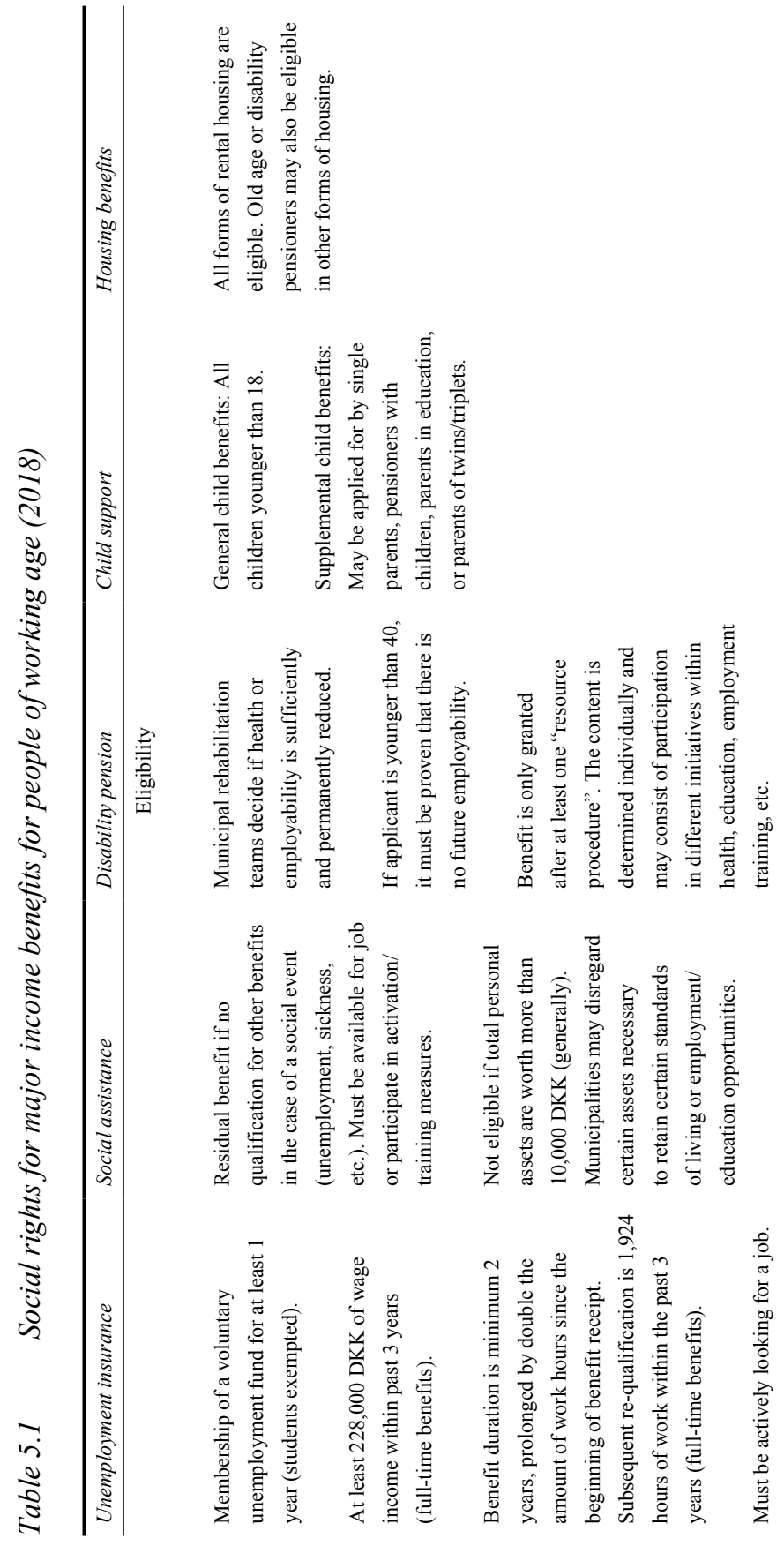



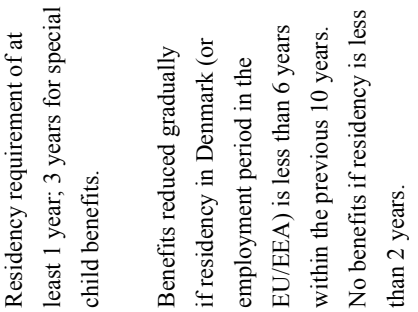

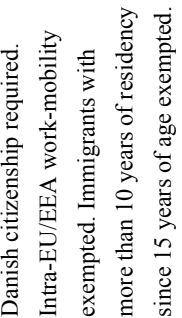

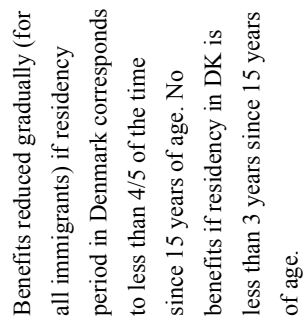

b 4

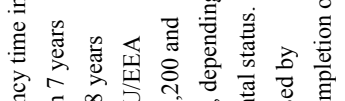

苛言 $\infty$ 至

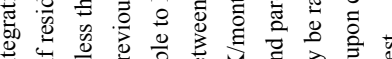

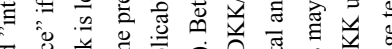

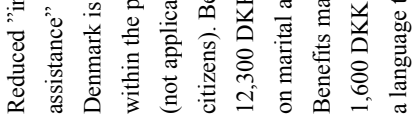

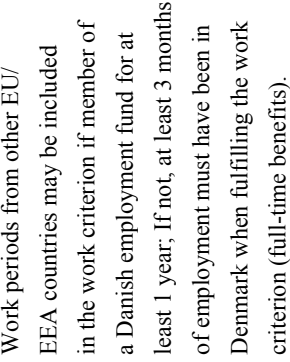




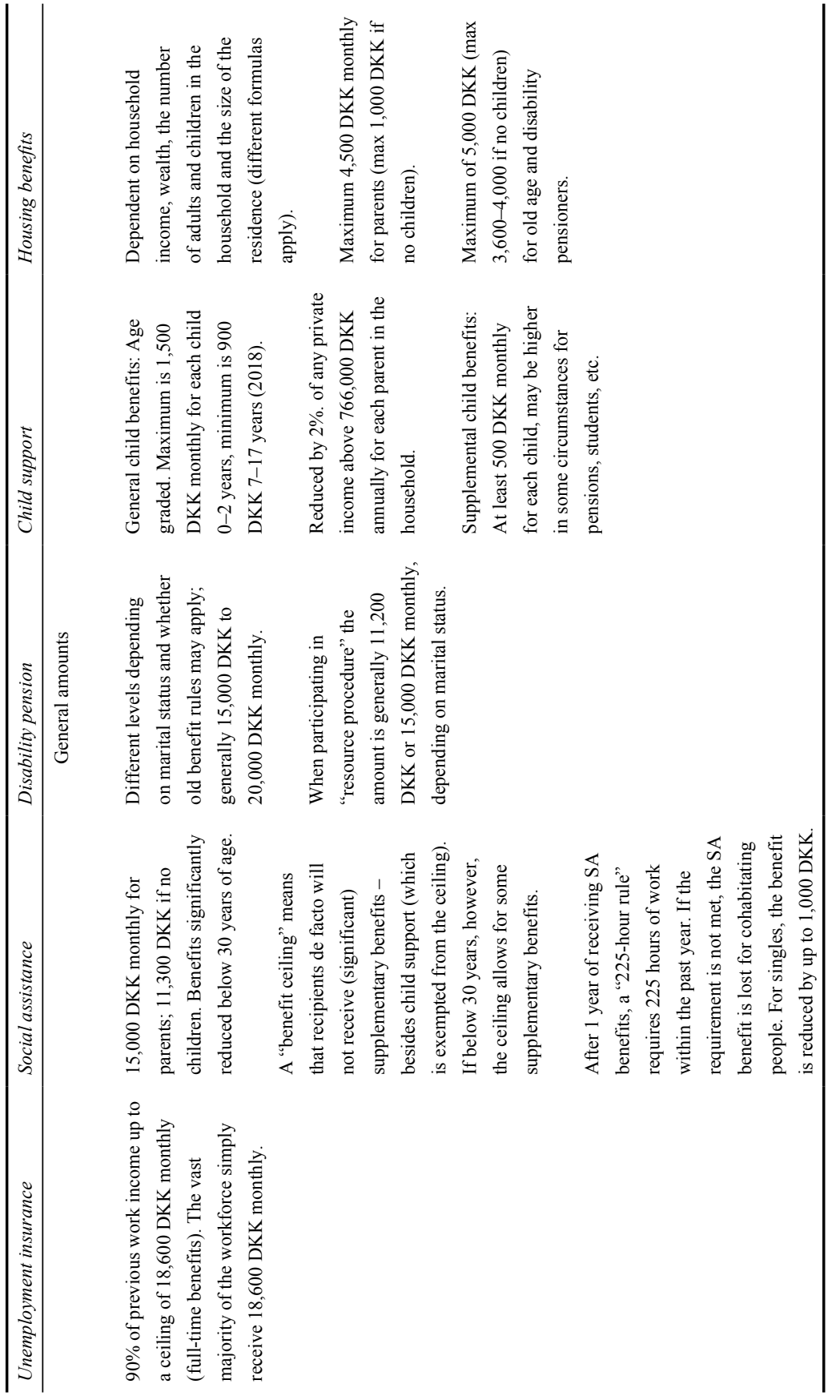




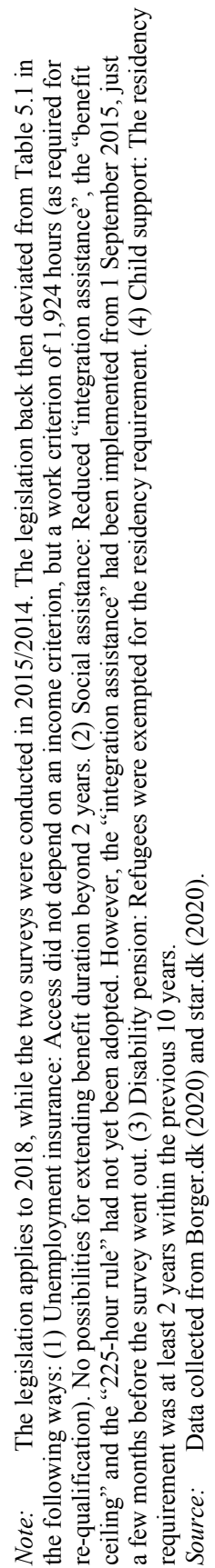


the old age pension, and later in 2018 for disability pension (the exemption was first removed in 2011, but the centre-left coalition that came to power that same year re-instated it in 2014).

\section{MEASURES OF TAXES AND BENEFITS}

The remainder of the chapter will show how our 14 immigrant groups and natives differ across nine measures of wages, taxes, and benefits. In Denmark, a few public reports on net contributions of migrants have figured prominently in public debates (Finansministeriet, 2018; Schultz-Nielsen \& Tranæs, 2014; Wadensjö \& Orrje, 2002). What we know from these reports lead us to expect considerable variation across our 14 migrant groups, and also a more basic divide between the migrant groups in the two surveys. We can broadly expect the Comcon nationalities to exhibit high amounts of benefit receipt and lower tax payments. The aforementioned reports routinely divide the immigrant population into Western and non-Western origins. The Ministry of Finance (Finansministeriet, 2018) and Schultz-Nielsen and Tranæs (2014) estimate large net public deficits for non-Western immigrants, and Comcon includes the five biggest nationalities from this group. The immigrants from Mifare are different in this respect, even though Mifare contains both so-called Western and non-Western immigrants. For instance, the Ministry of Finance (Finansministeriet, 2018) estimated that non-Western immigrants and descendants in total resulted in a net deficit of 36 billion DKK (4.8 billion EUR) in 2015. The figure for Western immigrants and descendants was a plus of 3 billion DKK ( 0.4 billion EUR). The figures include estimations of consumption of public services in addition to income benefits. Interestingly, both the Ministry of Finance (Finansministeriet, 2018) and Schultz-Nielsen and Tranæs (2014) show that most of the net deficit for non-Western descendants is simply due to the age composition of the group (most of them are below 18 years, and nearly all are below 40 years). When age is considered, non-Western descendants are significantly better integrated into the labour market, resulting in much smaller negative net contributions. The projections of Schultz-Nielsen \& Tranæs (2014) even estimated a small positive net-contribution from non-Western descendants by 2050. When distinguishing between migrant groups, all five groups covered by the Comcon survey exhibit significant negative net contributions per capita according to the Ministry of Finance (Finansministeriet, 2018), particularly migrants from Iraq and Lebanon. Among the groups covered by the Mifare survey, migrants of Turkish origin (which are also in Comcon) exhibit a negative net contribution, while most of the other groups show small negative or positive net contributions. American and British immigrants show relatively high positive net 
contributions. Estimations for Japanese immigrants are not included, probably because the group is quite small.

The calculations by the Ministry of Finance provide a basic insight into the net contribution from the 14 migrant groups covered by the book. However, as discussed in Chapter 3, the book only includes analyses of the first-generation migrants, which have been sampled in a particular way. Furthermore, the book only covers the migrants in the age group from 18 to 60 years old. Therefore, we provide a more detailed description of the respondents in the survey. As regards the specific measures in this chapter, we start by including wages. Work income can then be compared later on with social benefits. It should be noted that this does not include other sources of private income beyond wages. In other words, we have no indication of capital incomes, and so on. This means that we cannot see whether a few very rich people have been included in the survey. In addition, we can show total tax payments (from all sources of income). While income taxes are not high in general in Denmark, and both low-, mid-, and high-wage groups end up with a total income tax rate somewhat below the OECD average, the marginal tax for high incomes is somewhat above the OECD average (OECD, 2020c). Five other variables cover total benefits received as well as five sub-components. Three variables decompose total benefits into: (1) unemployment insurance, social assistance, and related benefits (see note to Table 5.2 for details), (2) disability pension, and (3) other benefits (see note to Table 5.2 for details). From "other benefits" we will also distinguish the two major forms of support outlined in Table 5.1, namely child support and housing subsidies. Finally, an overall measure subtracts income benefits from taxes. This variable simply indicates whether an individual gains more from the welfare in benefits than he or she pays in taxes. It should be emphasized once again that this book does not cover the consumption of public services. Table 5.2 shows us how all of the above measures vary by the survey respondents (weighted) and Figures 5.1 to 5.6 visualize the most important variations across the groups. We use an average over the year of the survey study and the two years before, that is, figures from 2012 to 2014 for the Comcon migrants and 2013 to 2015 for the Mifare migrants.

When considering Figures 5.1 and 5.2, we see a picture across nationalities that broadly match what we should expect based on the Ministry of Finance (Finansministeriet, 2018). The average migrant from the US or Great Britain looks very similar to an average native Dane in terms of wages, taxes, and benefits. Many of the other migrant groups from the Mifare survey do not exhibit very noticeable differences from the Danes as regards income benefits, but their wages are smaller. Migrants from Russia, however, do receive more in income benefits. The migrant groups from the Comcon survey (including Turkey in both surveys), on the other hand, receive both noticeably more in income benefits and less in wage incomes, particularly migrants from Iraq and 


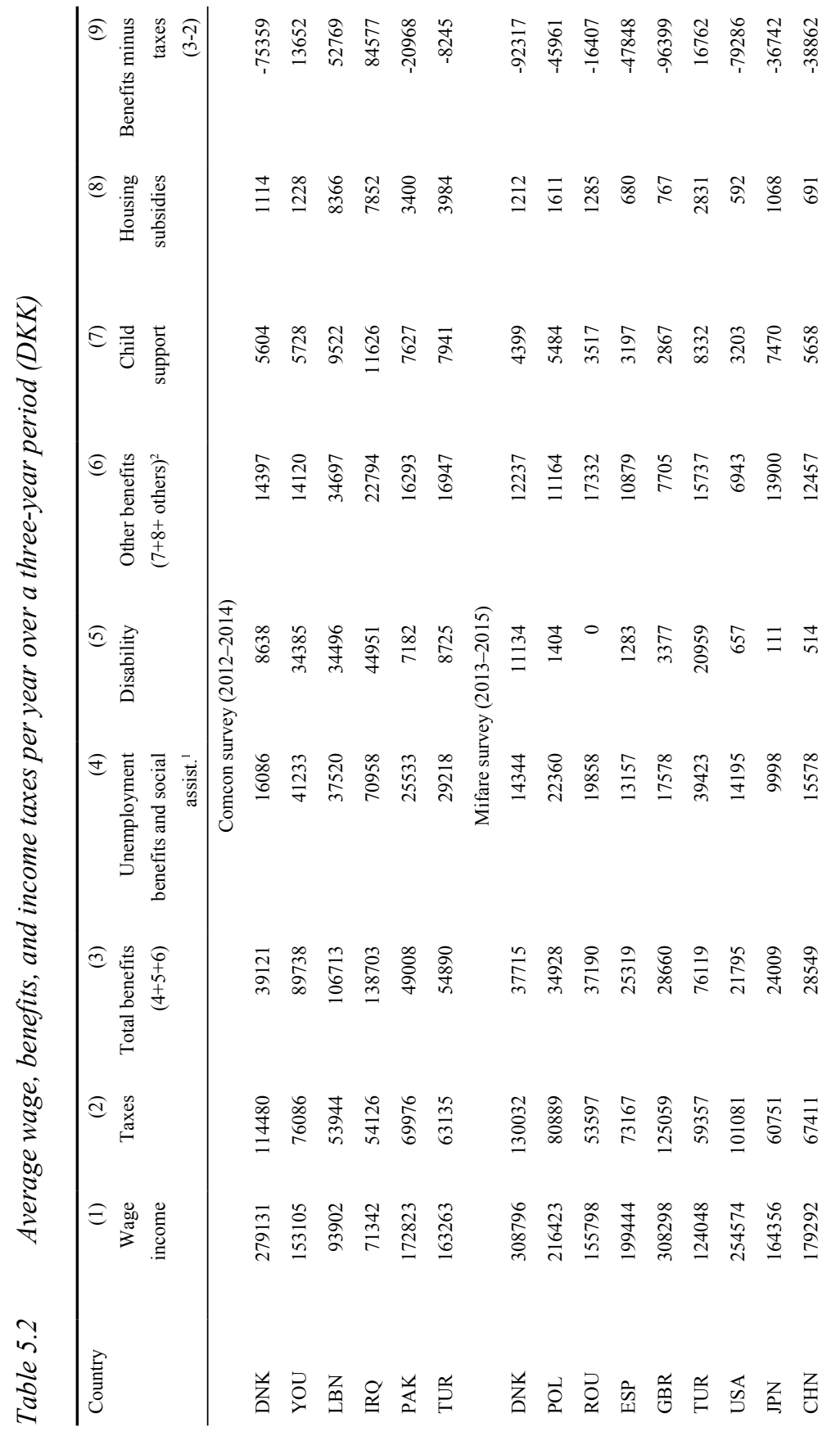




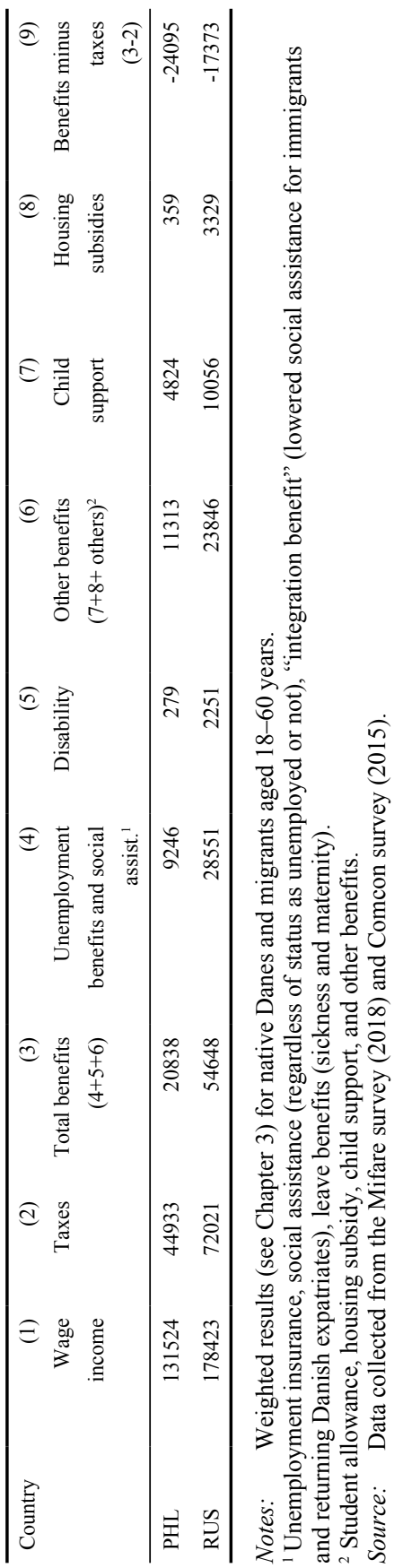


Lebanon. As mentioned before, we should also expect these two nationalities to be particularly noticeable when considering the report from the Ministry of Finance (Finansministeriet, 2018).

Figures 5.1 and 5.2 also show the income level when adding together wages and benefits, and subtracting the taxes paid in Denmark. When considering taxes, transfers, and wages as a measure of total disposable income, we notice the levelling effect of the welfare state. Disposable incomes are not that different for migrants in the Comcon survey, while there is more variation for migrants in the Mifare survey. This mainly reflects that the Comcon groups, have come to Denmark mostly via asylum or family reunification as described in the previous chapter. This picture might change in the future, considering the stricter residency requirements described in Table 5.1 and the removal of exemptions for refugees. The Mifare migrants, on the other hand, are presumably segregated into different wage segments on the labour market, and their generally employment-related migration means that they are not covered by the welfare state to the same extent. Hence, we see bigger differences in incomes. The poorest immigrants are the Japanese and Filipinos, while the richest are, as expected, the British.

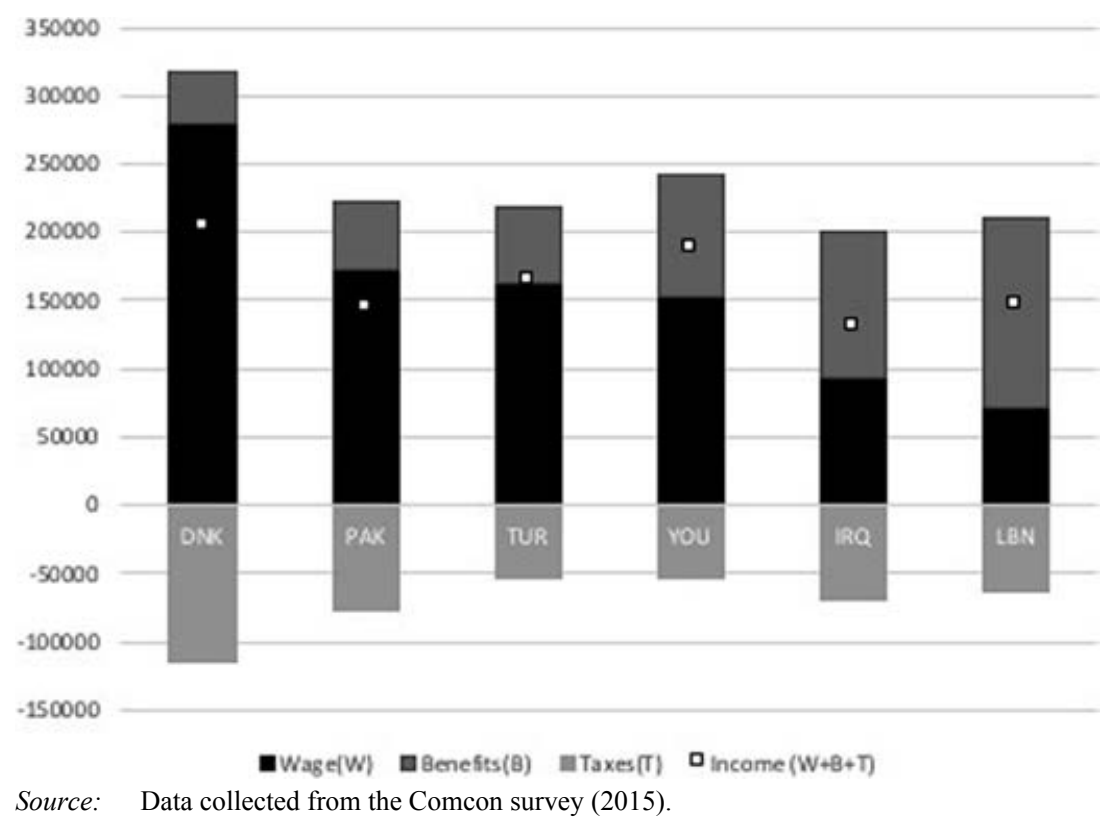

Figure 5.1 Wages, benefits, and taxes (DKK, annual averages 2012-2014), Comcon 


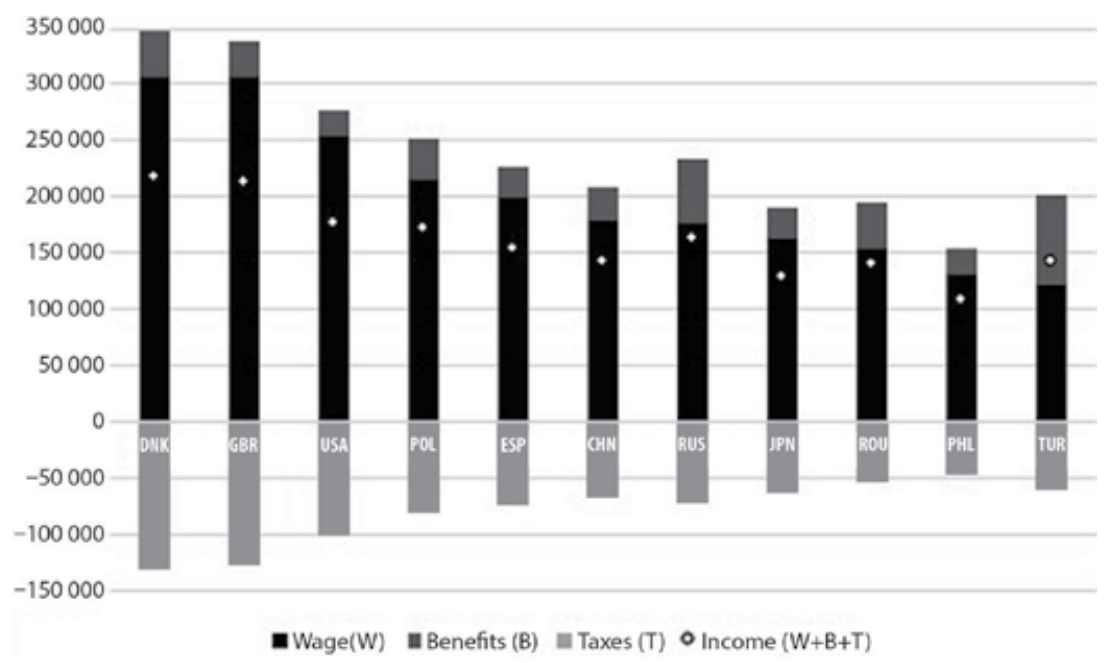

Source: Data collected from the Mifare survey (2018).

Figure $5.2 \quad$ Wages, benefits, and taxes (DKK, annual averages 2012-2014), Mifare

Figures 5.3 and 5.4 further decompose benefits into various types of benefit and show tax payments compared to the benefits received. Among the Comcon migrants, the migrants from ex-Yugoslavia, Iraq, and Lebanon are particularly overrepresented in disability benefits, but also unemployment insurance and social assistance. The migrants from Lebanon exhibit very high recipiency of all these benefits. For the Mifare migrants, on the other hand, recipiency of disability benefits is relatively low (except for migrants from Turkey). Here, variations in benefit incomes generally reflect variations in receipt of unemployment insurance and social assistance. Migrants from Poland and Russia receive relatively high amounts of these benefits.

The two figures also compare taxes with income benefits and present a measure of the extent to which respondents receive more in benefits than they pay in taxes (note once again that public services are not included here). For the Comcon survey, we find that the average native Dane of working age pays much more in taxes than he or she receives in benefits, while the migrants from ex-Yugoslavia, Iraq, and Lebanon receive more in benefits than they pay in taxes. For the Mifare survey, the pattern corresponds to what we should expect based on our previous observations. For most of these groups, the difference between taxes and benefits is smaller than for native Danes. American and British migrants, however, are once again more similar to the native Danes. 


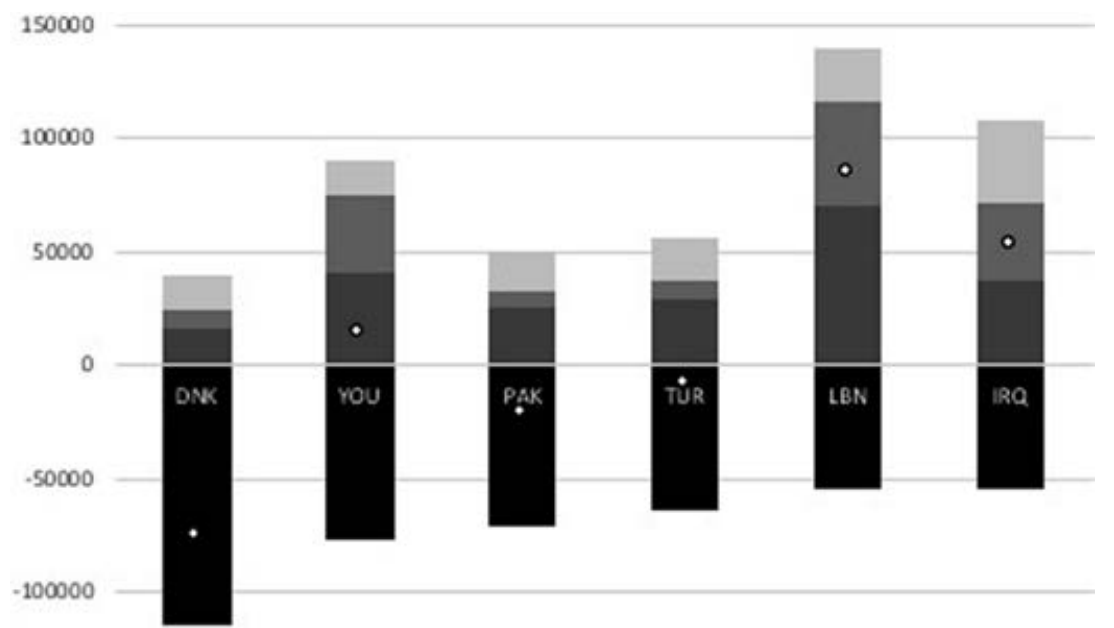

$-150000$

Source: Data collected from the Comcon survey (2015).

Figure 5.3 Benefit types and taxes (DKK, annual averages 2012-2014), Comcon

Besides averages across groups, there is naturally variation within our 14 migrant groups. Figures 5.5 and 5.6 depict the variation in wage income by migrant group. Benefits are not shown since variation by nationalities are relatively small and follow what would be expected from the previous figures. Taxes, unsurprisingly, mirror the wage variations below.

For native Danes (both surveys), we notice a group of people without any wage income, whereas the rest of our respondents exhibit a normal distribution, with a big group of wage earners between 300,000 and 400,000 DKK annually. The right tail of the distribution - high wage earners - is small, but long. Notice that the graphs have been capped at one million DKK. In other words, for better visualization of the distribution (shorter scale), respondents earning more than a million DKK are not included here. This affects primarily the British and American samples, where eight and seven millionaires respectively constitute 3.1 and 3.4 per cent of the survey respondents. In both Mifare and Comcon, they constitute 1.6 per cent of the native Danish samples. Other migrant groups in our surveys include 0 to 1 per cent millionaires. 
100000

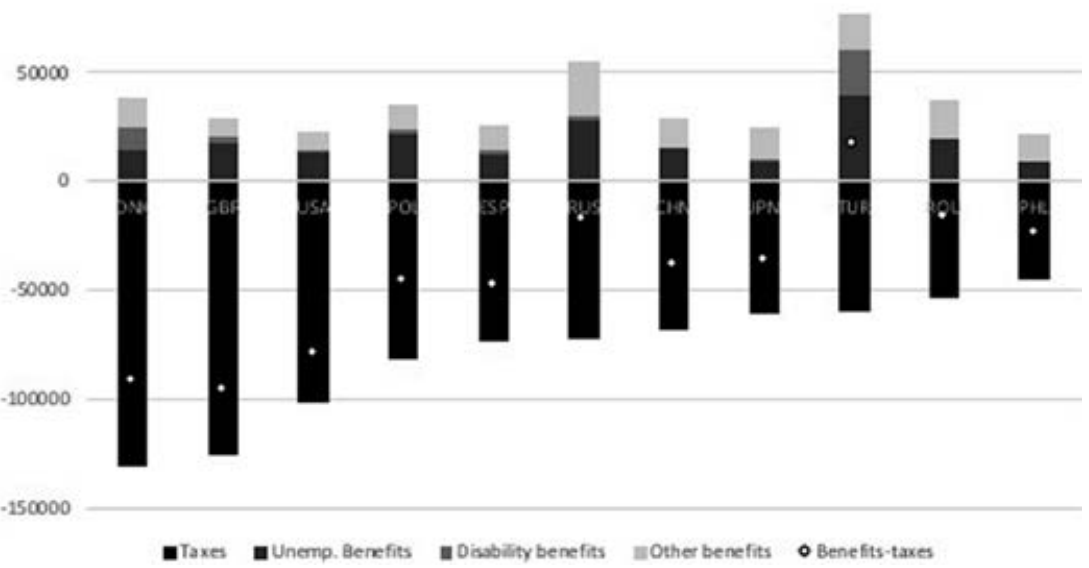

Source: Data collected from the Mifare survey (2018).

Figure 5.4 Benefit types and taxes (DKK, annual averages 2012-2014), Mifare

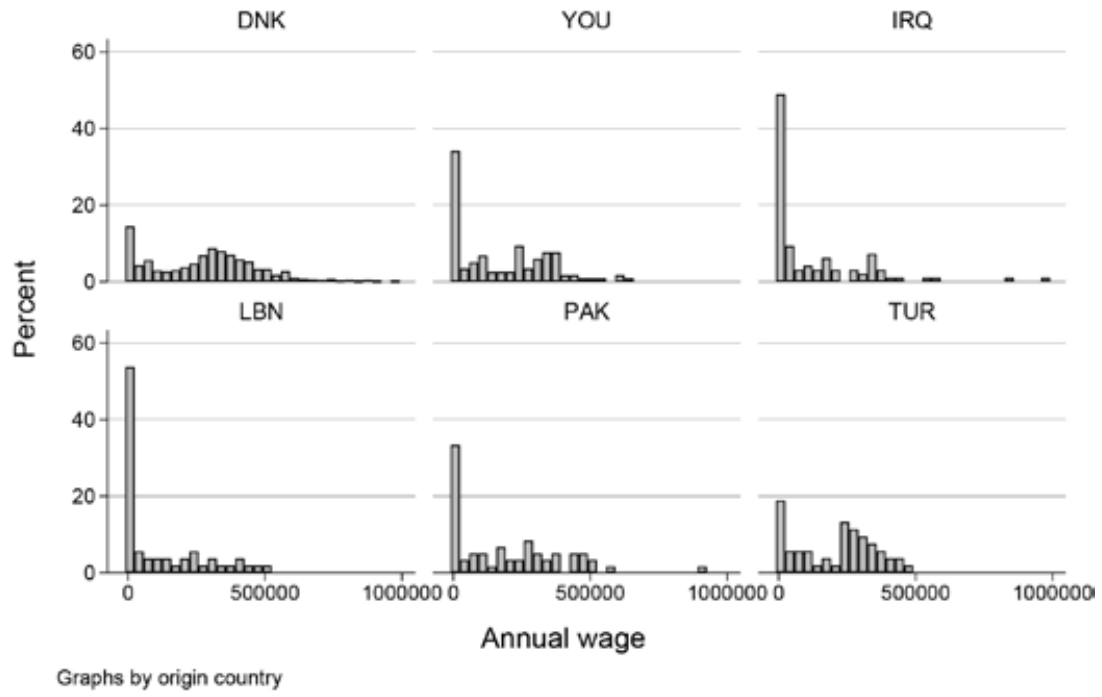

Note: $\quad$ Unweighted results for survey respondents.

Source: Data collected from the Comcon survey (2015).

Figure 5.5 Variation in annual average wages before taxes (2012-2014, DKK), Comcon 


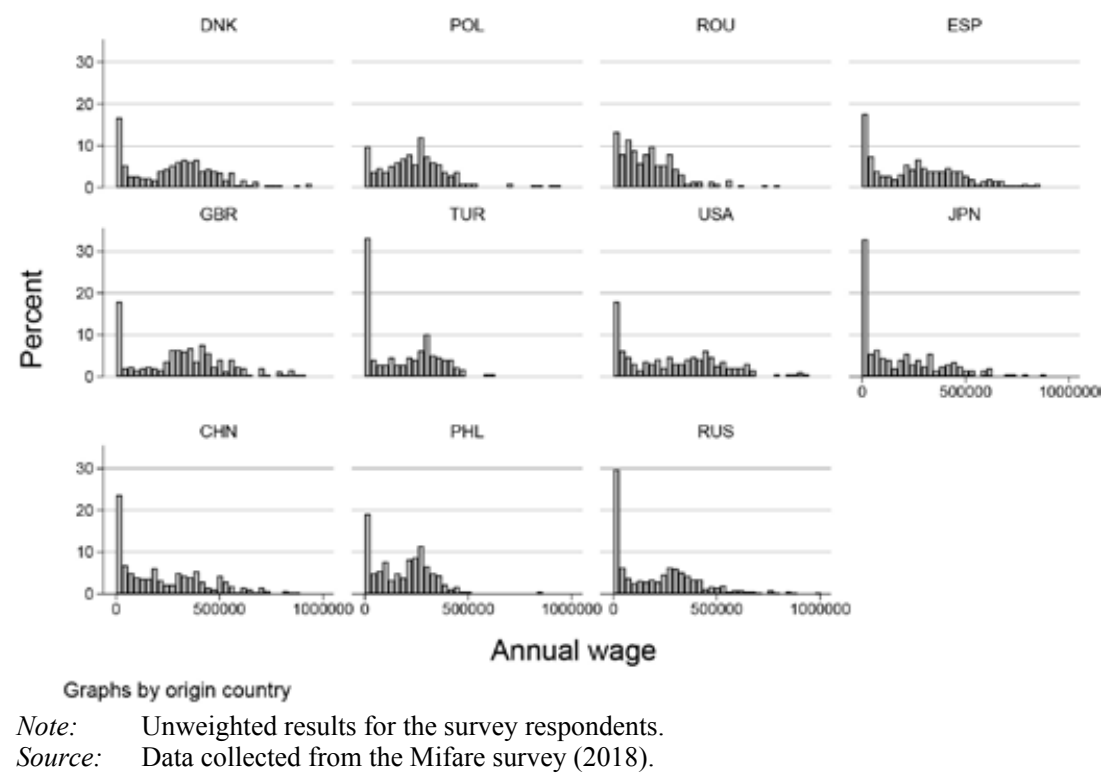

Figure 5.6 Variation in annual average wages before taxes (2013-2015, DKK), Mifare

As expected from previous figures, we identify the biggest group of non-wage earners among migrants for Iraq and Lebanon. In the Mifare-data, non-wage earners are most widespread among the migrants for Turkey. However, in both surveys, we also see that a group of Turkish immigrants are relatively successful with mid-level or high wages. We also see that most migrant groups have relatively few high-wage earners. The exceptions are migrants from the US or Britain, where we see a sizeable group of wage earners above 500,000 DKK. Among some of the group from the Mifare survey (Spain, Great Britain, USA, Japan, and China), we also see that wage variations are relatively large without any of the noticeable or pronounced peaks that we know from the standard normal distribution. The Eastern European migrants (Poland, Romania, and Russia), but also immigrants from the Philippines, on the other hand, are more concentrated around the low end of the wage scale.

\section{THE DANISH WELFARE STATE AND MIGRANTS' SELF-INTERESTS}

Traditional indicators of SEP are relatively poor indicators of potential self-interest concerning the welfare state. This book takes advantage of the 
possibilities that follow from linking survey to register data, and defines a range of measures of wages, benefits, and taxes that allow us to approach potential self-interest as closely as possible. Across the two surveys, the 14 migrant groups constitute a diverse array of groups vis-à-vis taxes paid and benefits received. Compared to the native Danes, the non-Western or Middle-Eastern migrants in the Comcon survey are quite reliant on income benefits, while wages, on the other hand, play a significantly smaller role as a source of income. This is most pronounced for migrants from ex-Yugoslavia, Pakistan, and particularly Lebanon. In the Mifare survey, the migrants from Asia, Eastern Europe, or Western countries receive a little less in income benefits, generally due to a smaller incidence of disability benefits, but their wages are often smaller as well. Migrants from the US and Great Britain, however, provide the biggest contrast to the Comcon migrants as their taxes paid and benefits received are similar to that of native Danes.

The overall conclusion of the chapter is that, as discussed in Chapter 2, the welfare institutions of the destination country do indeed influence SEP and thereby also the self-interest of various groups. This chapter has shown that access to benefits is conditioned on several specific criteria despite Denmark being categorized as a social-democratic universal welfare regime (see Chapters 1 and 2). The tightening of these criteria over the last two decades means that "free lunches" are rare; especially so for migrants relying on social assistance. However, we do study groups of migrants who receive more in benefits than they pay in taxes. Following the self-interest perspective discussed in Chapters 1 and 2, this would lead to attitudes in favour of the Danish welfare state. We also study groups of migrants who receive less in benefits than they pay in taxes, which within a self-interest perspective would lead to attitudes opposing the Danish welfare state. In the following chapter, we will see whether the migrants from the US and Great Britain are critical of the welfare state, while migrants from ex-Yugoslavia, Pakistan, and Lebanon are the most supportive of the welfare state. Furthermore, we will include the established indicators as control variables in the analyses to come, that is, we will describe how various variables, primarily the country of origin, are correlated with migrants' welfare attitudes controlled for self-interest effects. Following the discussion in Chapter 2, this is a way, far from a perfect one though, to distinguish between the logic of consequentiality theorized by rational choice institutionalism and the logic of appropriateness theorized by sociological institutionalism. 